\title{
IDENTIFIKASI DAN ANALISIS JEJAK KARBON (CARBON FOOTPRINT ) DARI PENGGUNAAN LISTRIK DI INSTITUT TEKNOLOGI YOGYAKARTA
}

\author{
Wikan Kusuma Admaja*, Nasirudin*, Handayani Sriwinarno* \\ *Teknik Lingkungan Institut Teknologi Yogyakarta \\ email : kusumawikan@gmail.com
}

\section{INTISARI}

Pemanasan global atau Global Warming adalah fenomenameningkatnya temperatur global dari tahun ke tahun karena terjadinya efek rumah kaca (greenhouse effect). Saat ini diperkirakan konsentrasi karbondioksida adalah yang paling dominan di atmosfer. Nilai emisi karbon yang dihasilkan oleh suatu organisasi, peristiwa, produk, dan aktivitas manusia disebut sebagai jejak karbon. Jejak karbon adalah suatu ukuran dari aktivitas manusia yang menimbulkan dampak terhadap lingkungan. Semakin banyak aktivitas yang dilakukan oleh manusia, maka semakin tinggi nilai emisi yang dihasilkan. Hal ini menunjukkan terjadinya hubungan antara aktivitas manusia dengan kualitas udara di atmosfer. Salah satu kontribusi pertama bagi suatu institusi untuk melakukan mitigasi pemanasan global adalah dengan menilai emisi gas rumah kaca yang dihasilkan dari kegiatan sendiri baik emisi langsung maupun tidak langsung. Penelitian tersebut bertujuan untuk mengetahui berapa besar emisi $\mathrm{CO}_{2}$ yang dihasilkan dari penggunaan listrik Institut Teknologi Yogyakarta, mengetahui sebaran jejak karbon dari tiap - tiap penggunaan alat elektronik di Institut Teknologi Yogyakarta, mengetahui berapa besar penurunan emisi $\mathrm{CO}_{2}$ yang dapat direduksi dari penghematan penggunaan listrik di Institut Teknologi Yogyakarta.

Metode yang dilakukan pada penelitian kali ini adalah kuantitatif. Metode kuantitatif adalah penelitian ilmiah yang sistematis terhadap bagian-bagian dan fenomena serta hubungan-hubungannya. Metode ini bertujuan untuk mengembangkan dan menggunakan model-model matematis, teori-teori dan hipotesis yang berkaitan dengan fenomena alam.

Hasil dari penelitian ini menunjukkan bahwa Institut Teknologi Yogyakarta menghasilkan jejak karbon (Carbon Footprint) dari penggunaan listrik sebesar $6951,589 \mathrm{KgCO}_{2}$ /bulan. Jadi setiap tahunnya Institut Teknologi Yogyakarta ratarata menghasilkan jejak karbon (Carbon Footprint) sebesar 83419,07 $\mathrm{KgCO}_{2} /$ tahun. Jejak karbon tertinggi dari penggunaan listrik ada pada ruang B sebesar 53,652 $\mathrm{KgCO}_{2}$. Untuk mengurangi jejak karbon, dapat dilakukan dengan cara Mematikan alat elektronik di waktu jam istirahat. Mematikan alat elektronik jika tidak dipakai. Menggunakan AC hanya pada waktu jam pelajaran saja.

Kata kunci: Global Warming, Jejak Karbon, $\mathrm{CO}_{2}$.

\section{IDENTIFICATION AND ANALYSIS OF CARBON FOOT (CARBON FOOTPRINT) FROM ELECTRICITY USE IN YOGYAKARTA INSTITUTE OF TECHNOLOGY}

\begin{abstract}
Global warming or Global Warming is a phenomenon of increasing global temperature from year to year due to the greenhouse effect. At present it is estimated that carbon dioxide concentrations are the most dominant in the atmosphere. The
\end{abstract}


value of carbon emissions produced by an organization, events, products and human activities is called a carbon footprint. Carbon footprint is a measure of human activity that has an impact on the environment. The more activities carried out by humans, the higher the emission value produced. This shows the relationship between human activity and air quality in the atmosphere. One of the first contributions for an institution to mitigate global warming is by assessing greenhouse gas emissions resulting from its own activities, both direct and indirect emissions. The study aims to find out how much $\mathrm{CO}_{2}$ emissions generated from the electricity use of the Yogyakarta Institute of Technology, knowing the distribution of carbon footprint from each use of electronic equipment at the Yogyakarta Institute of Technology, find out how much reduction in $\mathrm{CO}_{2}$ emissions can be reduced from electricity use savings at the Institute of Technology Yogyakarta.

The method used in this study is quantitative. Quantitative methods are systematic scientific research on parts and phenomena and their relationships. This method aims to develop and use mathematical models, theories and hypotheses related to natural phenomena.

The results of this study indicate that the Yogyakarta Institute of Technology produces a carbon footprint from electricity usage of $6951,589 \mathrm{KgCO}_{2} /$ month. So every year the Yogyakarta Institute of Technology on average produces a carbon footprint (Carbon Footprint) of $83419.07 \mathrm{KgCO}_{2} /$ year. The highest carbon footprint of electricity use is in room $\mathrm{B}$ of $53,652 \mathrm{KgCO}_{2}$. To reduce the carbon footprint, it can be done by Turning off electronic devices during breaks. Turn off electronic devices if not in use. Use AC only during class hours.

Keywords: Global Warming, Carbon Footprint, $\mathrm{CO}_{2}$.

\section{A. PENDAHULUAN}

Pemanasan global atau Global Warming adalah fenomenameningkatnya temperatur global dari tahun ke tahun karena terjadinya efek rumah kaca (greenhouse effect). Saat ini diperkirakan konsentrasi karbondioksida adalah yang paling dominan di atmosfer. Nilai emisi karbon yang dihasilkan oleh suatu organisasi, peristiwa, produk, dan aktivitas manusia disebut sebagai jejak karbon. Jejak karbon adalah suatu ukuran dari aktivitas manusia yang menimbulkan dampak terhadap lingkungan. Semakin banyak aktivitas yang dilakukan oleh manusia, maka semakin tinggi nilai emisi yang dihasilkan. Hal ini menunjukkan terjadinya hubungan antara aktivitas manusia dengan kualitas udara di atmosfer. Salah satu kontribusi pertama bagi suatu institusi untuk melakukan mitigasi pemanasan global adalah dengan menilai emisi gas rumah kaca yang dihasilkan dari kegiatan sendiri baik emisi langsung maupun tidak langsung. Penelitian tersebut bertujuan untuk mengetahui berapa besar emisi $\mathrm{CO}_{2}$ yang dihasilkan dari penggunaan listrik Institut Teknologi Yogyakarta, mengetahui sebaran jejak karbon dari tiap - tiap penggunaan alat elektronik di Institut Teknologi Yogyakarta, mengetahui cara penurunan jejak karbon di Institut Teknologi Yogyakarta. 
Nilai emisi karbon yang dihasilkan oleh suatu organisasi, peristiwa, produk, dan aktivitas manusia disebut sebagai jejak karbon. Jejak karbon dinyatakan dalam satuan ton karbon atau ton karbondioksida ekuivalen. Jejak karbon adalah suatu ukuran dari aktivitas manusia yang menimbulkan dampak terhadap lingkungan. Semakin banyak aktivitas yang dilakukan oleh manusia, maka semakin tinggi nilai emisi yang dihasilkan. Hal ini menunjukkan terjadinya hubungan antara aktivitas manusia dengan kualitas udara di atmosfer.

Setiap orang dalam aktivitasnya sehari-hari yang menggunakan energi akan menghasilkan emisi karbondioksida $\left(\mathrm{CO}_{2}\right)$, semakin banyak aktivitas manusia maka semakin banyak energi yang digunakan sehingga semakin besar nilai jejak karbonnya (Rahayu, 2011). Dalam IESR. (2011) dinyatakan bahwa saat ini kecenderungan orang untuk hidup senyaman mungkin mendorong munculnya kebiasaan hidup yang berdampak pada lingkungan. Kebiasaan menggunakan kendaraan pribadi terutama mobil dibandingkan dengan kendaraan umum, perjalanan dengan pesawat udara, penggunaan pendingin atau pemanas ruangan, penggunaan perangkat komputer, televisi, radio, dan perangkat hiburan lainnya adalah bentuk kebiasaan hidup yang berkontribusi terhadap banyaknya nilai jejak karbon.

\section{Metode}

Metode yang dilakukan pada penelitian kali ini adalah kuantitatif. Metode kuantitatif adalah penelitian ilmiah yang sistematis terhadap bagian-bagian dan fenomena serta hubungan-hubungannya. Metode ini bertujuan untuk mengembangkan dan menggunakan model-model matematis, teori-teori dan hipotesis yang berkaitan dengan fenomena alam.

\section{Hasil}

dan

PembahasanPerhitungan Faktor Emisi

Jumlah total emisi $\mathrm{CO}_{2}$ merupakan hasil perhitungan emisi $\mathrm{CO}_{2}$ yang diperoleh melalui penggunaan alat elektronik di Institut Teknologi Yogyakarta. Sebelum dilakukan perhitungan jejak karbon terlebih dahulu menghitung faktor emisi dari beberapa pembangkit listrik PLN. Berikut adalah perhitungan faktor emisi rata - rata :

Tabel 1. Perhitungan Faktor Emisi Rata- rata

\begin{tabular}{|l|c|l|l|l|l|}
\hline $\begin{array}{c}\text { Nama } \\
\text { Pembangkit }\end{array}$ & $\begin{array}{c}\text { Jenis } \\
\text { Pembangkit }\end{array}$ & Bahan Bakar & $\begin{array}{l}\text { Faktor Emisi } \\
\left(\mathrm{t} \mathrm{CO}_{2} / \mathrm{MWh}\right.\end{array}$ & $\begin{array}{l}\text { Kapasitas } \\
(\mathrm{MWh})\end{array}$ & $\left(\mathrm{t} \mathrm{CO}_{2}\right)$ \\
\cline { 3 - 6 } & & & 1 & 2 & $3=1 * 2$ \\
\hline UP Semarang & PLTGU & Gas & 0,4 & 1469 & 588 \\
\hline UP Paiton & PLTU & Batubara & 0,99 & 1230 & 1218 \\
\hline
\end{tabular}




\begin{tabular}{|l|l|l|l|l|l|}
\hline Swasta 1 & & & & \\
\hline $\begin{array}{l}\text { UP Paiton } \\
\text { Swasta 2 }\end{array}$ & PLTU & Batubara & 0,99 & 1300 & 1287 \\
\hline $\begin{array}{l}\text { UP Paiton } \\
\text { BUMN }\end{array}$ & PLTU & Batubara & 0,99 & 800 & 792 \\
\hline $\begin{array}{l}\text { UP Muara } \\
\text { Karang }\end{array}$ & PLTU & Batubara & 0,99 & 1000 & 990 \\
\cline { 2 - 6 } UP Cilacap & PLTGU & Gas & 0,4 & 200 & 80 \\
\hline UP Pacitan & PLTU & Batubara & 0,99 & 600 & 594 \\
\hline \multicolumn{7}{|c|}{ Total } & 0,99 & 630 & 624 \\
\hline \multicolumn{7}{|l|}{ Faktor emisi rata - rata $\left(\mathrm{kg} \mathrm{CO}_{2} / \mathrm{KWh}\right)$} & 7229 & 6172 \\
\hline
\end{tabular}

Data pemakaian listrik per bulan

Faktor emisi rata - rata = $\frac{\sum \text { (Faktoremisixkapasitasproduksi) }}{\sum \text { Kapastasproduksi }}$ KKapasitasproduksi

$$
\begin{aligned}
& =\frac{6172 \mathrm{tCO}_{2}}{7229 \mathrm{MWh}} \\
& =0,85 \frac{\mathrm{tCO}}{\mathrm{MWh}} \\
& =0,85 \frac{\mathrm{kgCO}}{\mathrm{kwh}}
\end{aligned}
$$

Setelah dirata - rata maka faktor emisi yang digunakan untuk perhitungan selanjutnya adalah 0,85 $\mathrm{kg} \mathrm{CO} / \mathrm{kwh}$.

\section{Jejak Karbon Penggunaan Listrik}

Besarnya jejak karbon yang dihasilkan dari penggunaan listrik bisa dilihat dari habisnya pemakaian listrik per bulan. Berikut adalah besarnya Kwh per bulan Institut Teknologi Yogyakarta :

Tabel 2. Pemakaian Listrik Per Bulan

\begin{tabular}{|c|c|c|c|c|c|c|}
\hline $\begin{array}{c}\text { Jan } \\
\text { uar }\end{array}$ & $\begin{array}{c}\text { Feb } \\
\text { rua }\end{array}$ & Ma & Apr & & Jun & $\begin{array}{c}\text { rata } \\
\text { i }\end{array}$ \\
ri & ret & il & Mei & i & rata \\
\hline 84 & 662 & 97 & 106 & 105 & 30 & 817 \\
41, & 2,5 & 65, & 25, & 75, & 40, & 8,3 \\
04 & 3 & 76 & 22 & 11 & 38 & 4 \\
\hline
\end{tabular}
tersebut digunakan untuk mencari besaran jejak karbon yang dihasilkan dari penggunaan listrik di Institut Teknologi Yogyakarta. Pada tabel 3 menunjukan rata - rata jejak karbon dari penggunaan listrik di Institut Teknologi Yogyakarta

Tabel 3. Jejak Karbon Penggunaan Listrik

\begin{tabular}{|c|c|c|c|}
\hline $\begin{array}{c}\text { Bula } \\
\mathrm{n}\end{array}$ & Kwh & $\begin{array}{c}\text { Faktor } \\
\text { Emisi }\end{array}$ & $\begin{array}{c}\text { Emisi } \mathrm{CO}_{2} \\
\left(\mathrm{KgCO}_{2}\right)\end{array}$ \\
\hline $\begin{array}{c}\text { janua } \\
\text { ri }\end{array}$ & $\begin{array}{c}8441, \\
04\end{array}$ & 0,85 & 7174,884 \\
\hline $\begin{array}{c}\text { Febru } \\
\text { ari }\end{array}$ & $\begin{array}{c}6622, \\
53\end{array}$ & 0,85 & 5629,1505 \\
\hline $\begin{array}{c}\text { Mare } \\
\text { t }\end{array}$ & $\begin{array}{c}9765, \\
76\end{array}$ & 0,85 & 8300,896 \\
\hline april & $\begin{array}{c}10625 \\
, 22\end{array}$ & 0,85 & 9031,437 \\
\hline Mei & $\begin{array}{c}10575 \\
, 11\end{array}$ & 0,85 & 8988,8435 \\
\hline \multicolumn{3}{|c|}{ Rata - rata } & 6940, \\
Juni & 38 & 0,85 & 2584,323 \\
\hline \multicolumn{4}{|c|}{} \\
\hline
\end{tabular}

Tabel di atas menunjukan bahwa besaran jejak kabon dari penggunaan listrik perbulan rata ratanya adalah 6951,589 $\mathrm{KgCO}_{2}$ /bulan. Maka dalam satu 
tahun Institut Teknologi Yogyakarta menghasilkan jejak karbon sebesar $83419,07 \mathrm{KgCO}_{2} /$ tahun.

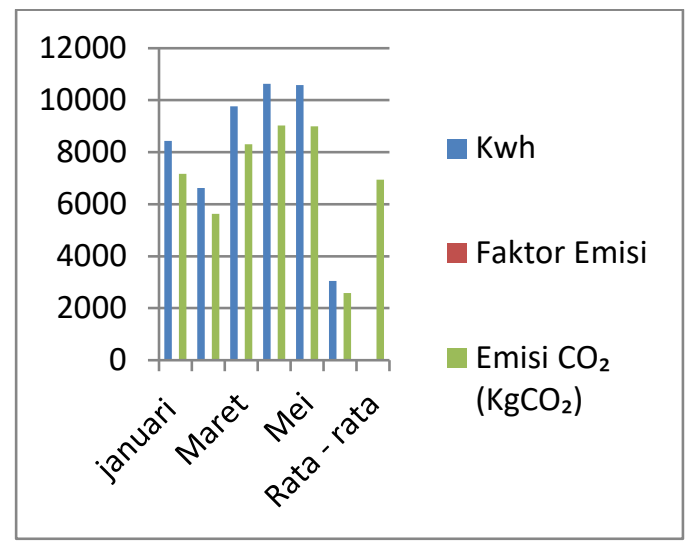

Gambar 1. Jejak Karbon Per Bulan

Dari diagram diatas menunjukan emisi tertinggi ada bulan april yaitu sebesar 9031,437 $\mathrm{KgCO}_{2}$. Hal tersebut dapat dipengaruhi oleh lamanya alat elektronik yang digunakan setiap harinya. Sedangkan emisi terendah ada pada bulan Juni sebesar 2584,323 $\mathrm{KgCO}_{2}$. Pada bulan Juni tersebut terjadi penurunan emisi karena berkurangnya aktifitas penggunaan alat elektronik yang ada di Institut Teknologi Yogyakarta.

\section{Sebaran Jejak Karbon Berdasarkan Alat Elektronik}

Setiap alat elektronik menghasilkan jejak karbon yang berbeda - beda karena memiliki daya dan lama pemakaian yang berbeda beda pula. Pada setiap ruangan memiliki jejak karbon yang bervariasi. Ruang B yang ada di lantai 1 memiliki jejak karbon paling tinggi yaitu $53,652 \mathrm{KgCO}_{2}$ /hari. $\mathrm{Hal}$ itu disebabkan karena banyaknya alat elektronik yang ada di ruang itu. Penyebab lainya juga di ruang $\mathrm{B}$ memiliki AC yang berdaya 5000 watt jadi membuat jejak karbon lebih tinggi jika dibandingkan dengan ruangan lainnya. Berikut adalah jejak karbon yang dihasilkan dari setiap alat elektronik yang ada di Institut Teknologi Yogyakarta :

Tabel 4. Jejak Karbon Setiap Alat Elektronik

\begin{tabular}{|l|r|}
\hline Alat elektronik & Emisi $\left(\mathrm{Kg} \mathrm{CO}_{2}\right)$ \\
\hline Lampu & 27,3564 \\
\hline PC & 55,25 \\
\hline AC & 346,256 \\
\hline Printer & 1,0846 \\
\hline Kipas Angin & 3,06 \\
\hline Dispenser & 4,08 \\
\hline TV & 4,488 \\
\hline Proyektor & 15,606 \\
\hline Jumlah & 457,181 \\
\hline
\end{tabular}

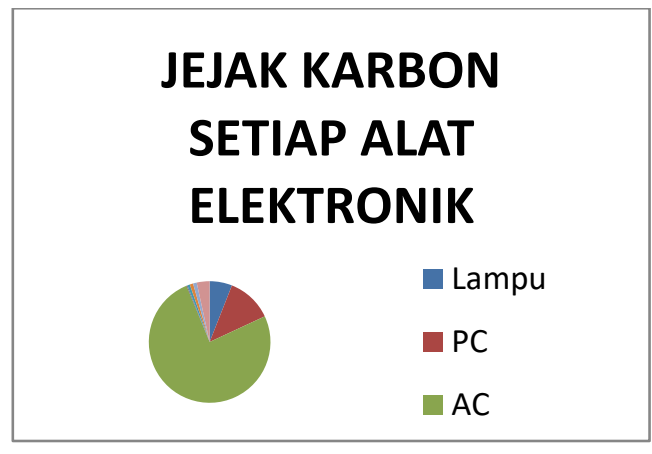

Gambar 2. Jejak Karbon setiap Alat Elektronik

Dari gambar diatas menunjukan bahwa AC menghasilkan jejak karbon yang 
paling besar. AC menghasilkan jejak karbon paling banyak karena memiliki daya yang yang tinggi sehingga konsumsi listriknya menjadi banyak. Sedangkan printer menghasilkan jejak karbon paling rendah karena dari segi jumlah printer memiliki jumlah yang paling sedikit dan juga printer memiliki penyerapan daya listrik yang kecil. Besar kecilnya jejak karbon dipengaruhi oleh beberapa hal seperti penyerapan daya listrik setiap alat elektronik, lamanya jumlah pemakaian dan jumlah alat elektronik yang digunakan.

\section{Pemetaan Jejak Karbon}

Pemetaan jejak karbon dilakukan dengan menggunakan software Autocad untuk mengetahui ruang mana yang memiliki emisi yang tinggi dan rendah dengan menggunakan warna, untuk menentukan range tinggi dan rendah.

Emisi Rendah (hijau) $=0-30$ $\mathrm{KgCO}_{2}$

Emisi Tinggi $($ merah $)=>30$ $\mathrm{KgCO}_{2}$

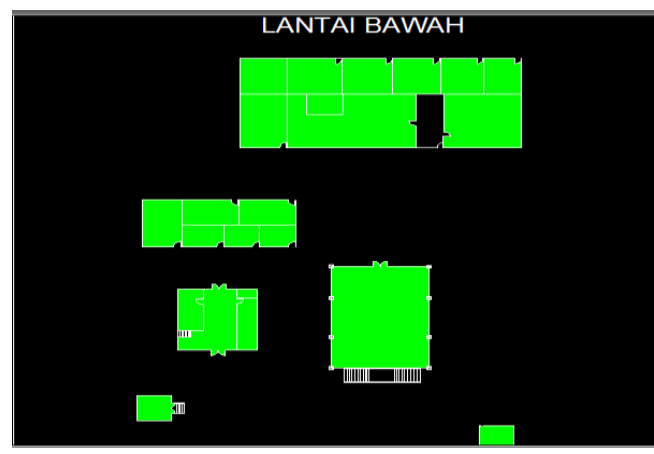

Gambar 3. Pemetaan Jejak Karbon Lantai Bawah

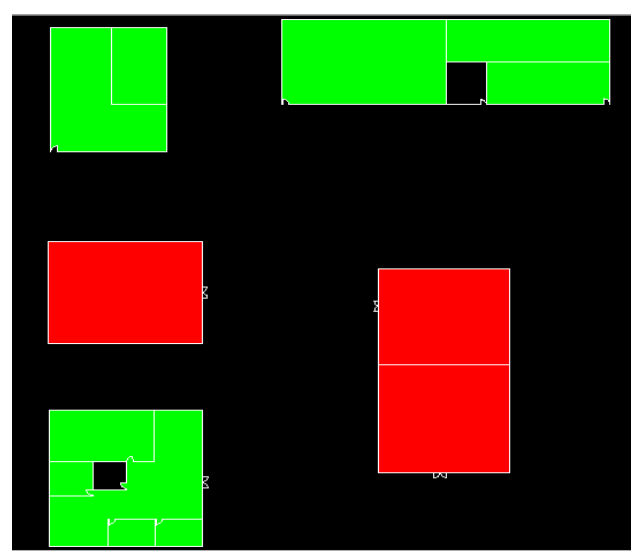

Gambar 4. Pemetaan Jejak Karbon Lantai 1

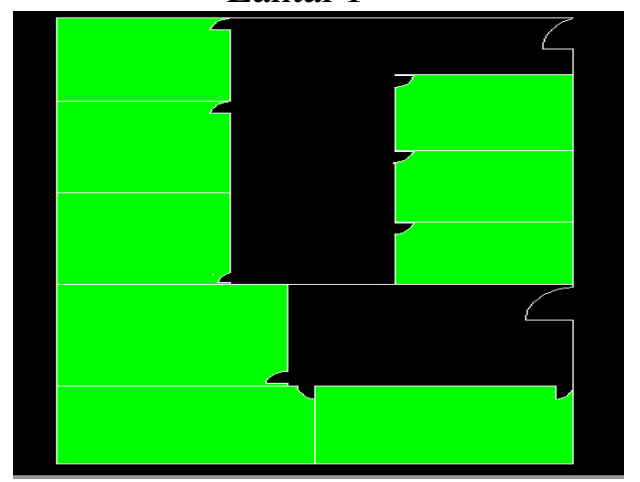

Gambar 5. Pemetaan Jejak Karbon Lantai 2

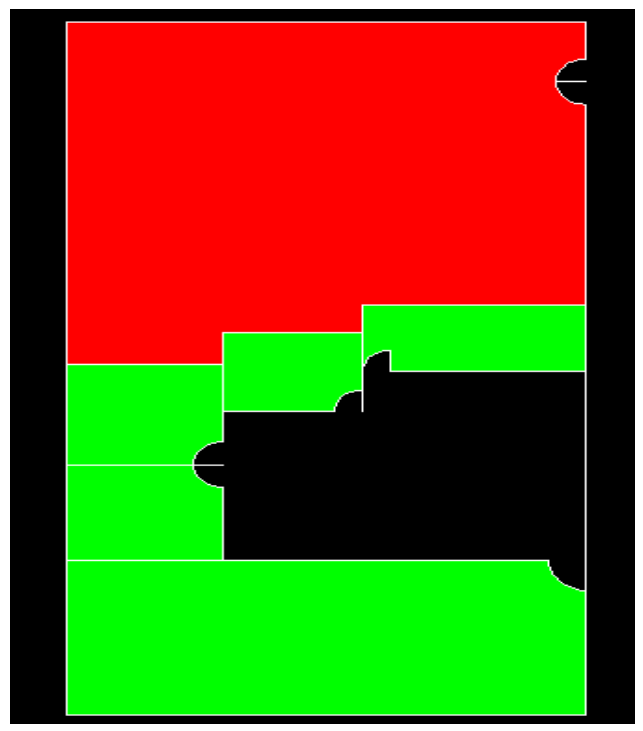


Gambar 6. Pemetaan Jejak Karbon Lantai 3

Pada ruangan yang ada di lantai bawah memiliki jejak karbon yang rendah. Hal itu disebabkan oleh alat - alat elektronik yang dikapai memiliki penyerapan daya listrik yang rendah. Selain itu juga di lokasi lantai bawah tidak memiliki alat elektronik yang cukup banyak. Sedangkan jejak karbon yang tergolong tinggi ada ruang $\mathrm{B}$, ruang $\mathrm{C}$, ruang $\mathrm{H}$ dan ruang perpustakaan.

\section{Biaya Penggunaan Listrik}

Biaya penggunaan listrik dihitung dari berapa habisnya kwh per bulan yang dikalikan dengan tarif dasar listrik. Institut Teknologi Yogyakarta termasuk dalam golongan sosial yang artinya mendapat subsidi dari pemerintah. Berikut adalah tarif dasar listrik sosial (subsidi) :

Tabel 5. Tarif Dasar Listrik Sosial ( Subsidi )

\begin{tabular}{|c|c|}
\hline Golongan Tarif/ Daya & $\begin{array}{c}\text { Tarif } \\
\text { (Rp/Kwh) }\end{array}$ \\
\hline S-1/220VA & - \\
\hline S-2/450VA & 325 \\
\hline S-2/900VA & 455 \\
\hline S-2/1300VA & 708 \\
\hline S-2/2200VA & 760 \\
\hline S-2/3500VA - 200 kVA & 900 \\
\hline S-3/ di atas 200 kVA & - \\
\hline
\end{tabular}

Institut

Teknologi Yogyakarta masuk kedalam golongan S-2/3500VA - 200kVA karena memiliki daya 58kVA. Maka dari itu kwh per bulan yang telah dipakai dikali dengan 900. Berikut adalah biaya listrik per bulan Institut Teknologi Yogyakarta :

Tabel 6. Biaya Listrik Per Bulan

\begin{tabular}{|c|c|c|c|c|c|c|}
\hline B & & Feb & & & & \\
ul & Jan & ruar & Ma & Apr & & Jun \\
uari & i & ret & il & Mei & i \\
\hline K & 844 & 662 & 976 & 106 & 105 & 304 \\
W & 1,0 & 2,5 & 5,7 & 25, & 75, & 0,3 \\
h & 4 & 3 & 6 & 22 & 11 & 8 \\
\hline Bi & 759 & 596 & 878 & 956 & 951 & 273 \\
ay & 693 & 027 & 918 & 269 & 759 & 634 \\
a & 6 & 7 & 4 & 8 & 9 & 2 \\
\hline
\end{tabular}

Dari tabel berikut menunjukan biaya penggunaan listrik tertinggi ada pada bulan April yaitu sebesar Rp 9.562.698. Pada bulan Juni biaya penggunaan listrik mengalami penurunan menjadi $\mathrm{Rp}$. 2.736.342.

\section{Rekomendasi Pereduksian}

Ada beberapa hal yang yang perlu dilakukan dalam upaya untuk menurunkan jejak karbon di Institut Teknologi Yogyakarta. Upaya upaya yang perlu dilakukan antara lain :

1. Menggunakan listrik secara bijak.

2. Mematikan alat elektronik di waktu jam istirahat.

3. Mematikan alat elektronik jika tidak dipakai.

4. Menggunakan AC hanya pada waktu jam pelajaran saja.

5. Melepas kabel alat elektronik jika tidak dipakai. 
6. Mengganti AC yang berdaya tinggi ke yang lebih rendah.

7. Mematikan alat elektronik pada saat meninggalkan ruangan.

\section{Kesimpulan}

Berdasarkan analisis jejak
karbon (carbon footprint)
dilakukan di Institut Teknologi
Yogyakarta didapat kesimpulan
sebagaiberikut:
1. Institut Teknologi Yogyakarta
menghasilkan jejak karbon
(Carbon Footprint) dari
penggunaan listrik sebesar
6951,589 KgCO $/$ bulan. Jadi
setiap tahunnya Institut
Teknologi Yogyakarta rata-rata
menghasilkan jejak karbon
(Carbon Footprint) sebesar
83419,07 $\mathrm{KgCO}_{2} /$ tahun.

2. Jejak karbon tertinggi dari penggunaan listrik ada pada ruang $\mathrm{B}$ sebesar 53,652 $\mathrm{KgCO}_{2}$

3. Ada beberapa cara untuk mengurangi jejak karbon dengan melakukan hal sebagai berikut :

- Mematikan alat elektronik di waktu jam istirahat.

- Mematikan alat elektronik jika tidak dipakai.

- Menggunakan AC hanya pada waktu jam pelajaran saja.

\section{Saran}

1. Mengganti lampu neon menjadi lampu led.
2. Mengganti AC yang berdaya tinggi ke yang lebih rendah.

3. Mematikan alat elektronik saat meninggalkan ruangan.

\section{DAFTAR PUSTAKA}

Anonim. 2010. Faktor Emisi tentang definisi pengertian faktor emisi, perhitungan faktor emisi.

Anonim. 1996. Revised 1996 Intergovernmental Panel on Climate Change (IPCC) Guidelines for National Green house Gas.

Anonim. 2006. Revised 2006 Intergovernmental Panel on Climate Change (IPCC) Guidelines for National Green house Gas.

Hairiah, K. 2007. Perubahan Iklim Global: Penyebab Terjadinya Peningkatan GRK. Universitas Brawijaya, Fakultas Pertanian: Malang.

Harmoni, A. 2009. Dampak Sosial Ekonomi Perubahan Iklim. Fakultas Ilmu Komputer dan Teknologi Informasi, Universitas Gunadarma: Jakarta.

Puri, A.R. 2011. Kajian Emisi $\mathrm{CO}_{2}$ Berdasarkan Tapak Karbon Sekunder dari Kegiatan Non Akademik di ITS Surabaya. Tugas Akhir. ITS

Sejati Kuncoro. 2011. "Global Warming, Food, And Water" Problems, Solutions, and The Changes of World Geopolitical 
Constellation. Gadjah Mada

University Press, Yogyakarta.

Walser, M.L. 2010. Carbon

Footprint. Articles of

Encilopedia of Earth.

URL:http://www.eoearth.org/ar

ticle/carbon_foottprint

Wicaksono, A.M. 2011. Studi

Carbon Footprint $\left(\mathrm{CO}_{2}\right)$ dari

Kegiatan Pemukiman di

Surabaya Bagian Barat. Tugas

Akhir. ITS Surabaya.

Wiedmann, T. Dan Minx, J. 2008."Environmental Impact Assesment Review"A

Definition of 'Carbon

Footprint'. In: C. C. Pertsova,

Ecological Economics

Research Trends: Chapter 1,

pp. 1-11, Nova Science

Publishers, Hauppauge NY,

USA. (Italy) as a case study,

Vol 29, pp. 39-5 
